\title{
WATER-SOLUBLE POLYMERIC IONIC 5-FLUOROURACIL COMPLEX BASED ON METHACRYLIC ACID COPOLYMERS
}

\author{
OLGA V. ZHUKOVA ${ }^{1}$, SERGEY A. RYABOV ${ }^{2}$, SERGEY D. ZAITSEV ${ }^{2}$, OLGA V. KUZNETSOVA ${ }^{3}$, DARIA M. GAVRILOVA ${ }^{1}$, \\ EUGENIA V. ARCHIPOVA ${ }^{1}$, ANNA A. GOLOVACHEVA ${ }^{2}$, YULIA S. VOLKOVA ${ }^{2}$
}

${ }^{1}$ Privolzhsky Research Medical University, Russia, ${ }^{2}$ National Research Lobachevsky State University of Nizhny Novgorod, Russia, ${ }^{3}$ G. A. Razuvaev Institute of Organometallic Chemistry, Russian Academy of Sciences, Russia

Email: ov-zhukova@mail.ru

Received: 04 Mar 2019, Revised and Accepted: 10 May 2019

\section{ABSTRACT}

Objective: The objective of this work was to obtain a water-soluble 5-fluorouracil (5-FU) polymeric complex on the basis of a methacrylic acid (MAA) copolymer to be used as an injectable chemotherapeutic agent.

Methods: A polymeric carrier was synthesized using tert-butyl methacrylate (TBMA) as a monomer, thioglycolic acid, and azobisisobutyronitrile as a radical polymerization initiator. The polymer was converted by acid hydrolysis into a water-soluble copolymer of TBMA and MAA of 20: 80 mass \%, respectively. The copolymer of TBMA and MAA was modified with 5-FU. Their formation was proved using IR and UV spectroscopy. The particle size of the 5-FU polymeric complex was estimated by turbidimetry, which is based on measuring the intensity of light transmitted through a disperse system. The release of 5-FU from the obtained ionic complexes by dialysis in vitro was evaluated.

Results: Polymeric carriers were obtained with different amounts of 5-FU $(5,15,25,50 \mathrm{~mol} \%)$. A high peak at $\lambda=266 \mathrm{~nm}$ was observed in the UV spectrum of the polymeric carrier (characteristic of 5-FU). The particle size was estimated at $13 \mathrm{~nm}$ for the complex with $5 \mathrm{~mol} \% 5$-FU and $26.8 \mathrm{n}$ for the complex with $50 \mathrm{~mol} \% 5$-FU. The 5-FU release was estimated in two parallel experiments at $37{ }^{\circ} \mathrm{C}$. One utilized a phosphate-citrate buffer with $\mathrm{pH} 5.0$ to model the intracellular space and the other, a phosphate buffer with $\mathrm{pH} 7.4$ to model the intravascular space. Two systems, with 5 and $15 \mathrm{~mol} \%$ 5-FU, were chosen for testing. In both phosphate buffer and phosphate-citrate buffer, 5-FU was released from the polymeric complex with $5 \mathrm{~mol} \%$ 5-FU approximately 1.3 times faster than from the complex containing $5 \mathrm{~mol} \% 5$-fluorouracil. The kinetics of 5-FU release from the polymeric complex ( $5 \mathrm{~mol} \% 5$-fluorouracil) showed that the 5 -FU release was $77.9 \%$ in phosphate-citrate buffer and $59.6 \%$ in phosphate buffer over $52 \mathrm{~h}$ of dialysis. When the 5-FU release kinetics was studied with the polymeric complex containing 15 mol\% 5-FU, the 5-FU release was $100.0 \%$ in phosphate-citrate buffer and $75.1 \%$ in phosphate buffer over $57 \mathrm{~h}$ of dialysis.

Conclusion: Water-soluble nanoscale complexes of 5-FU with TBMA-MAA copolymers extend application of 5-FU, while its general toxicity might be lower. The complexes are sufficiently stable at $\mathrm{pH} 7.4$ and readily release 5-FU at pH 5.0.

Keywords: 5-fluorouracil, Water-soluble polymeric complex, Copolymer of $t$-butylmethacrylate, Methacrylic acid, Polymeric carrier

(C) 2019 The Authors. Published by Innovare Academic Sciences Pvt Ltd. This is an open access article under the CC BY license (http://creativecommons.org/licenses/by/4.0/) DOI: http://dx.doi.org/10.22159/ijap.2019v11i4.32919

\section{INTRODUCTION}

5-Fluorouracil (5-FU) is a chemotherapeutic agent and is broadly used to treat oncology diseases. 5-FU is used to treat a variety of solid tumors [1, 2], including colorectal [3-5], breast [6], pancreatic [7], and gastric [8] cancers.

Because 5-FU is metabolized rapidly, it is of immense importance to maintain its serum concentrations at high levels to improve the therapeutic efficacy. However, high risk of severe toxicity is involved in using 5-FU at high concentrations [9].

Systems for controlled release of 5-FU have been the focus of many studies described in the literature. Many of the systems are based on polypeptides and polysaccharides. Such systems are often capable of improving 5-FU treatment parameters [10].

Chitosan derivatives are commonly used as carriers [11]. Chitosan is biodegradable, biocompatible, inexpensive, minimally immunogenic, and low cytotoxic and has consequently found broad application [12]. Moreover, chitosan has functional groups that allow a simple binding of vectors and drugs. Yet its poor solubility limits its use as a carrier for drug delivery [13]. Water-soluble polymeric carriers are therefore necessary to design to achieve successful drug delivery.

Polymethacrylates are a widely available class of polymers. Poly(methacrylic acid) (PMMA) and poly(acrylic acid) are watersoluble polymers and have carboxylic functional groups to allow their modification.

In 2016, a PMMA conjugate with gold nanoparticles and doxorubicin attached through an acid-labile cysteine bond was tested for anticancer properties in vitro and in vivo [14]. A high efficacy for both chemotherapy and radiation therapy was demonstrated for the conjugate in a human cervical adenocarcinoma cell line.

A universal pH-sensitive nanoparticle system was proposed for selective drug delivery in 2011, using PMMA as a component [15]. Chitosan and PMMA were coated on mesoporous silica nanoparticles. Doxorubicin was used as a model drug to study nanoparticle behavior in conditions simulating those in biological media. The study showed that doxorubicin could be efficiently loaded into the resulting microspheres. The cumulative release was $\mathrm{pH}$ dependent. The doxorubicin release rate at low $\mathrm{pH}$ (5.5) was far faster than at $\mathrm{pH}$ 7.4. Cytotoxicity testing by the MTT assay showed that empty carrier microspheres were suitable as drug carriers. A similar system was described in 2014 [16]. A high encapsulating capacity for doxorubicin was demonstrated again for nanoparticles. The drug was readily released in response to a shift towards acidic $\mathrm{pH}$ (5.0).

Poly (acrylic acid) is promising as a drug carrier because it is biocompatible and bioadhesive, the property being due to its carboxylic groups, which produce hydrogen bonds with mucin and glycoprotein on mucous membranes. Poly (acrylic acid) is temperature and $\mathrm{pH}$ sensitive. A new potential application of poly (acrylic acid) gels is delivering anticancer drugs in the gastrointestinal tract after their oral administration [17]. A polymeric system based on a chitosan-poly (acrylic acid) copolymer has been proposed for oral 5-FU delivery to treat colorectal cancer.

The objective of this work was to obtain a water-soluble 5-FU polymeric complex on the basis of a methacrylic acid (MAA) copolymer to be used as an injectable chemotherapeutic agent. 


\section{MATERIALS AND METHODS}

\section{Materials}

For synthesis of the polymer carrier, the following reagents were used: tert-butyl methacrylate (TBMA) as a monomer (98\%, Aldrich); thioglycolic acid (TGA), azobisisobutyronitrile (AIBN) as a radical polymerization initiator. 5-fluorouracil (5-FU) was used for the preparation of the polymer complex. AIBN was purified by recrystallization from isopropyl alcohol and dried in a vacuum oven to constant weight. Reagents purchased from catalogs were not subjected to additional purification. TGA was purified by distillation in vacuo. Solvents, such as acetonitrile and tetrahydrofuran (THF), were purified by standard techniques [18].

\section{Methods}

Polymerization of TBMA was carried out in bulk in the presence of $5 \cdot 10^{-2}$ $\mathrm{M}$ AIBN and TGA as a chain transfer agent at $70^{\circ} \mathrm{C}$. Initial reaction mixtures were added into dilatometric ampoules and degassed via three freezing-thawing cycles under vacuum; the ampoules were sealed then. The polymer was purified by triple precipitation from acetone with water and dried under vacuum to a constant weight.

To estimate the molecular weight (MW) of a polymer, gel permeation chromatography (GPC) was run in tetrahydrofuran (TGF) at $40{ }^{\circ} \mathrm{C}$, using polymethacrylate standards and a Prominence LC-20VP liquid chromatography system with two Styragel columns (pore sizes $10^{6}$ and $10^{5} \AA$ ) and a differential refractometer.

PolyTBMA hydrolysis was carried out in dioxane supplemented with diluted $\mathrm{HCl}$ (1: 2), using $0.5 \mathrm{ml}$ of the solution per $0.25 \mathrm{~g}$ of the polymer. The reaction was performed in a flask fitted with a reflux condenser at 60,80 , and $100^{\circ} \mathrm{C}$. MAA units were quantified by potentiometric acid-base titration with $0.1 \mathrm{~N} \mathrm{KOH} \mathrm{(a} \mathrm{methanolic}$ solution) in methanol.

\section{Generation of a polymeric complex with 5-FU}

A TBMA-MAA copolymer was dissolved in water and added to a 5FU solution in acetonitrile. The resulting mixture was incubated in the dark with continuous stirring on an electromagnetic stirrer for $48 \mathrm{~h}$. The solvent was removed, and the powder mixture was dried in an oven at $40{ }^{\circ} \mathrm{C}$ to a constant weight.

UV spectra were recorded using a Shimadzu UV 1650 DC spectrometer (working range 190-1100 nm, wavelength accuracy $0.3 \mathrm{~nm}$ ). Substances to be tested were dissolved in water, a phosphate buffer ( $\mathrm{pH}$ 7.4), and a phosphate-citrate buffer ( $\mathrm{pH}$ 5.0) to $0.002 \mathrm{mg} / 5 \mathrm{ml}$.

\section{IR spectroscopy}

IR spectra of test substances were recorded using a FSM 1201 Fouriertransform IR spectrometer (Monitoring, St. Petersburg, Russia) in a range of 400-4000 $\mathrm{cm}^{-1}$ (resolution $4 \mathrm{~cm}^{-1}$, number of scans 32, $\mathrm{KBr}$ windows). Samples were obtained as suspensions in mineral oil.

Nuclear magnetic resonance ( ${ }^{1} \mathrm{H}$ NMR) spectra were recorded using a Bruker FT-80 spectrometer. The spectrometer frequency was $400 \mathrm{MHz}$; the chemical shift $\delta$ was recorded against a tetramethylsilane internal standard.

\section{Estimation of the particle size for the 5-FU polymeric complex}

The particle size of the 5-FU polymeric complex was estimated by turbidimetry, which is based on measuring the intensity of light transmitted through a disperse system. Polymeric complexes were used as $0.1 \%$ aqueous solutions. The optical density was measured using a photoelectric colorimeter with red and blue filters for each polymeric complex. The turbidity $\tau$ was calculated from Equation (1):

$$
\tau=\frac{2.3 D}{x}=\frac{2.3 \lg \left(I_{0} / I_{n}\right)}{x}
$$

Where $I_{n}$ and $I_{0}$ are the transmitted and incident light intensities, respectively; $x$ is the sample path length; $\tau$ is the sample turbidity; and $D$ is the optical density. The parameter $k$ was then calculated from Equation (2):

$$
k=\frac{\lg \tau_{2}-\lg \tau_{1}}{\lg \lambda_{2}-\lg \lambda_{1}}
$$

Where $\lambda$ is the wavelength, $\tau$ is the turbidity, and $k$ is the wavelength exponent in Heller's equation.

Equation (3) was used to obtain the $Z$ value corresponding to the given $k$ :

$$
Z=67 \exp \{-0.87 k\}
$$

The particle size of the polymeric complex was calculated from Equation (4):

$$
Z=\frac{8 \pi r}{\lambda_{m}}
$$

Where $r$ is the particle radius and $\lambda_{m}$ is the arithmetic mean wavelength used in the experiment.

\section{Estimation of the 5-FU release from the polymeric carrier in vitro}

The 5-FU release was measured in a buffer solution at $\mathrm{pH} 5.0$ and 7.4. A polymeric complex was dissolved in the buffer solution to $1 \mathrm{mg} / \mathrm{ml}$, and the resulting sample was added into a chamber of a dialysis cell. A buffer with the $\mathrm{pH}$ of interest was added into the other chamber. The chambers had a CelluSep T1 membrane (MW $3500 \mathrm{Da}$ ) between them. The cell was incubated in a thermostat at $37^{\circ} \mathrm{C}$. Aliquots (the total contents) were taken from the buffer chamber at certain time points to measure the free $5-\mathrm{FU}$ content at $266 \mathrm{~nm}$.

\section{RESULTS AND DISCUSSION}

Poly-TBMA (PTBMA) was chosen as a basis for 5-FU polymeric complexes because the polymer is simple to synthesize and then to hydrolyze to yield water-soluble TBMA-MAA copolymers or PMMA. TBMA was polymerized in the presence of AIBN (5·10-2 M) as a radical polymerization initiator and TGA as a chain transfer agent (Scheme 1).

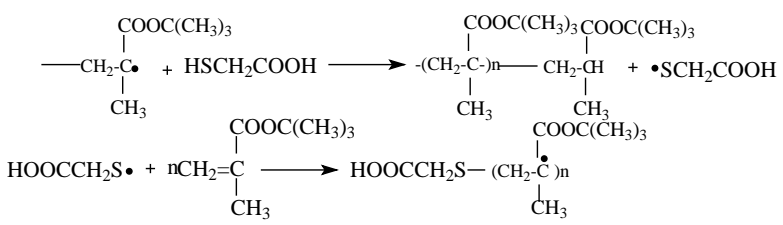

Scheme 1: The reaction of chain transfer to TGA in the course of TBMA radical polymerization

As a chain transfer agent, TGA makes it possible to control both the MW and MW distribution (MWD) (table 1).

Table 1: Effect of the TGA content (wt \%) on the MW characteristics of PTBMA

\begin{tabular}{lll}
\hline TGA content, wt\% & $\mathbf{M}_{\mathbf{n}}, \mathbf{D a}$ & $\mathbf{M}_{\mathbf{w}} / \mathbf{M}_{\mathbf{n}}$ \\
\hline 0 & 231600 & 2.98 \\
0.5 & 18000 & 1.95 \\
0.75 & 13900 & 1.80 \\
1 & 12400 & 1.35 \\
\hline
\end{tabular}


When TGA was used as $1 \mathrm{wt} \%$, conversion of $~ 98 \%$ was achieved in $4 \mathrm{~h}$ and the resulting PTBMA had characteristics optimal for biocompatible polymers, that is, a low molecular weight and a low dispersity $\left(M_{\mathrm{n}}=12400\right.$ and $\left.M_{\mathrm{w}} / M_{\mathrm{n}}=1.35\right)$.

Next, we studied the kinetics of PTBMA acid hydrolysis to obtain a biocompatible polymer with MAA units. As is seen from Scheme 2, PTBMA hydrolysis is autocatalytic and is irreversible because gaseous isobutylene is yielded.

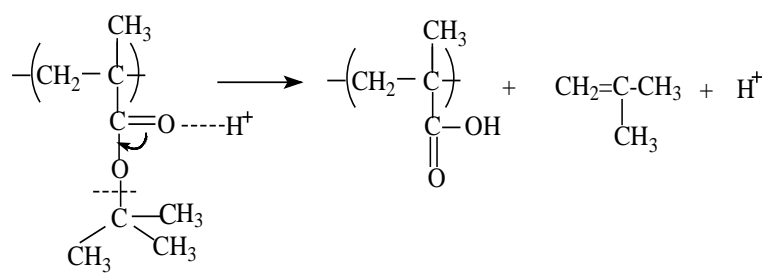

Scheme 2: Acid hydrolysis of PTBMA

To estimate the activation energy of the process, experiments were performed at 60,80 , and $100^{\circ} \mathrm{C}$. An Arrhenius plot was constructed from the results and used to calculate the activation energy of acid hydrolysis of PTBMA; $E_{\mathrm{a}}=9.34 \mathrm{~kJ} / \mathrm{mol}$. The low $E_{\mathrm{a}}$ value suggests a high rate for acid hydrolysis of PTBMA, providing optimal conditions for generating a polymer with necessary properties.

An $80 \%$ conversion was achieved when PTBMA was hydrolyzed at $100{ }^{\circ} \mathrm{C}$ for $12 \mathrm{~h}$; i.e., a TBMA-MAA copolymer with a component proportion of 20: $80 \mathrm{wt} \%$ was obtained (Scheme 3).

The process was verified by NMR spectroscopy (fig. 1). A new peak at $12.28 \mathrm{ppm}$, suggesting generation of carboxyl groups, became detectable in the sample after hydrolysis.

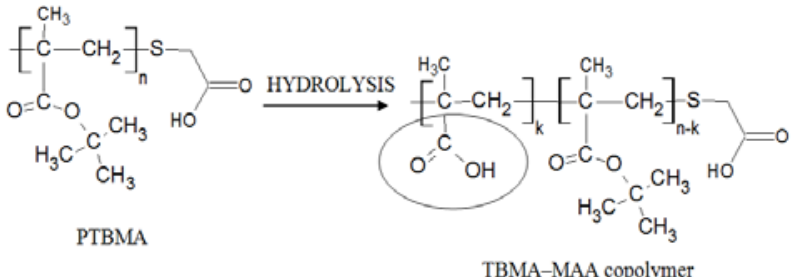

Scheme 3: Production of a TBMA-MAA copolymer via PTBMA hydrolysis

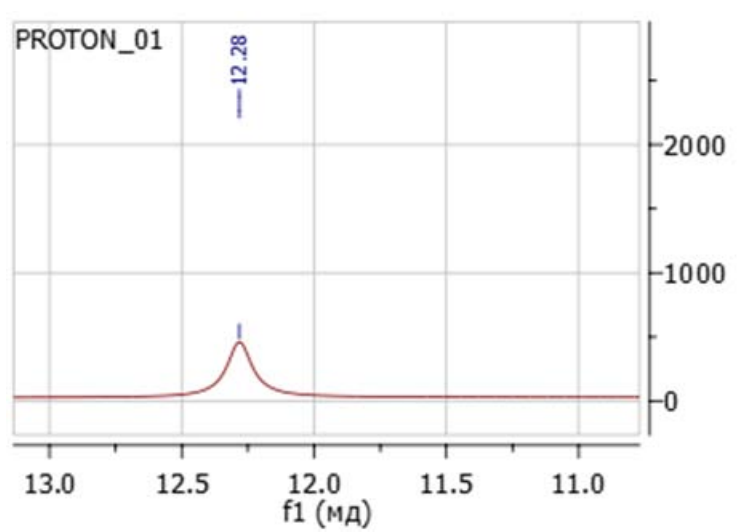

Fig. 1: Fragment of the 1H-NMR spectrum obtained for a PTBMA sample after its hydrolysis

Complexes of 5-FU with the TBMA-MAA copolymer were obtained at the next step of the study (table 2).

Table 2: 5-FU content (mol \%) in polymeric complexes with TBMA-MAA

\begin{tabular}{ll}
\hline Polymeric carrier & 5-FU loading amount (mol\%) \\
\hline & 5 \\
TBMA-MAA (80 wt $\%), M_{n}=12400, M_{w} / M_{n}=1.35$ & 15 \\
& 25 \\
\hline
\end{tabular}

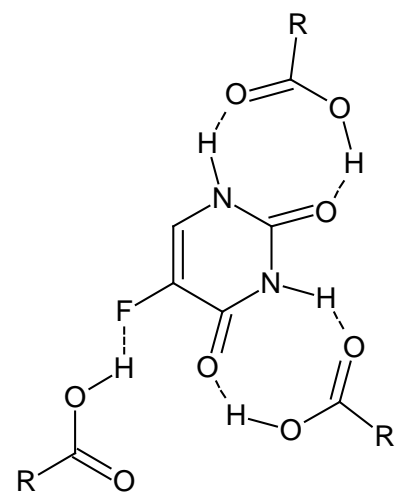

Fig. 2: Intermolecular interaction between 5-FU and a MAA carboxyl group of the TBMA-MAA copolymer. $R$ is the TBMAMAA copolymer moiety

Intermolecular interactions between 5-FU and carboxyl groups of MAA residues of the copolymer (Scheme 3) yielded a water-soluble polymeric complex (fig. 2-4).
The intermolecular interaction includes a hydrogen bonding of the electronegative fluorine atom of 5-FU and the hydrogen atom that carries a partial positive charge and is covalently bound with the electronegative oxygen atom in the MAA carboxyl group. Additional hydrogen bonds arise between the hydrogen of the-NH group of the pyrimidine ring and an oxygen of the MAA residue and between oxygen and hydrogen atoms in the MAA residue. The mechanism indicates that 5-FU is fully complementary to the MAA residue. A 5FU molecule binds fully two MAA residues and, partly, a third MAA residue.

The formation of an intermolecular complex between 5-FU and the TBMA-MAA copolymer was confirmed by IR and UV spectroscopy data (table 3).

The results of IR spectroscopy are consistent with the results of other researchers. The $\mathrm{C}=\mathrm{O}$ of polymer closes by bands from $\mathrm{C}=\mathrm{O}$ of 5 -FU, but we see bands of $\mathrm{OH}$ from $\mathrm{COOH}$ in the IR-spectrum. The $\mathrm{C}=\mathrm{O}$ stretching vibrations of heterocyclic imide and amide groups are observed at 1725 and $1673 \mathrm{~cm}^{-1}$, respectively. $\mathrm{N}-\mathrm{H}$ bending is observed at $1504 \mathrm{~cm}^{-1}[21,22]$.

A high peak at $\lambda=266 \mathrm{~nm}$ was observed in the UV spectrum of the polymeric complex. The peak was characteristic of 5-FU and absent from the spectrum of the TBMA-MAA copolymer (fig. 3). 
Table 3: IR spectrum peaks of 5-FU, TBMA-MAA copolymer and ionic complex of TBMA-MAA copolymer and 5-FU

\begin{tabular}{|c|c|c|}
\hline IR spectrum peaks & TBMA-MAA copolymer & $\begin{array}{l}\text { Ionic complex of TBMA-MAA copolymer } \\
\text { and 5-FU }\end{array}$ \\
\hline Broad peak at $3500-3000 \mathrm{~cm}^{-1}$ & $\mathrm{OH}$ (carboxyl group) & OH (carboxyl group) \\
\hline $1725 \mathrm{~cm}^{-1}, 1673 \mathrm{~cm}^{-1}$ & \multicolumn{2}{|r|}{$\mathrm{C}=\mathrm{O}$ stretching vibrations of heterocyclic imide and amide groups } \\
\hline $1580-1520 \mathrm{~cm}^{-1}$ & - & Fluctuations of the ring \\
\hline $1504 \mathrm{~cm}^{-1}$ & - & $\begin{array}{l}\text { N-H Bending } \\
\text { Vibrations } \\
\text { Valence fluctuations } \\
\text { of the ring }\end{array}$ \\
\hline $1247 \mathrm{~cm}^{-1}$ & - & $\mathrm{C}-\mathrm{F}[19]$ \\
\hline $880 \mathrm{~cm}^{-1}$ & & Fluctuations of the ring[20] \\
\hline $816 \mathrm{~cm}^{-1}$ & - & C-F [20] \\
\hline
\end{tabular}

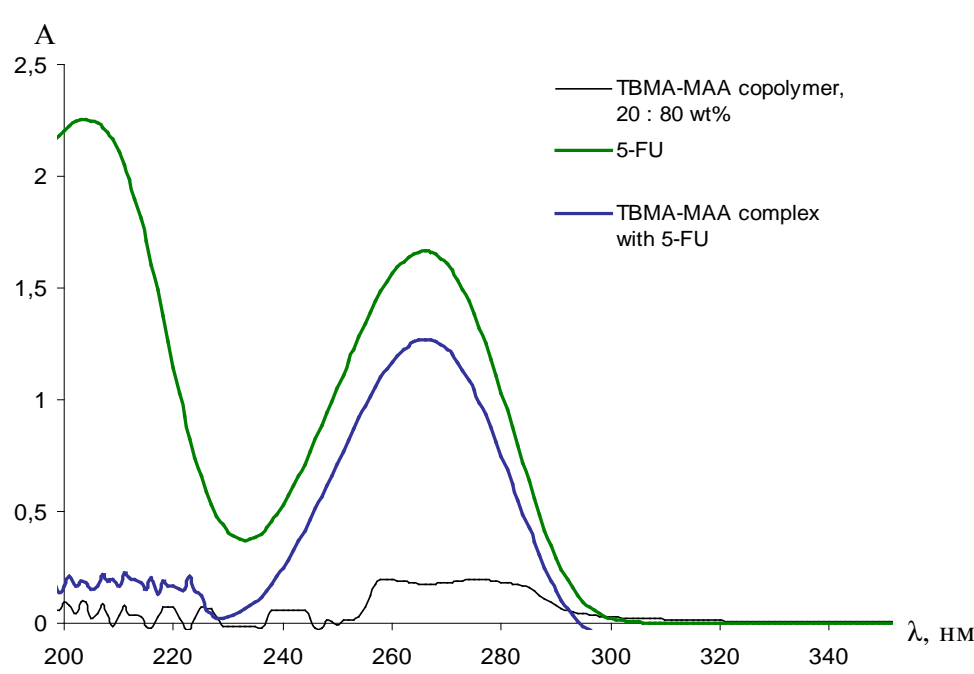

Fig. 3: UV spectra of $5-\mathrm{FU}\left(2 \cdot 10^{-8} \mathrm{~g} / \mathrm{ml}\right.$, a 100 -fold dilution), the TBMA-MAA copolymer $\left(20: 80 \mathrm{wt} \%, 4 \cdot 10^{-7} \mathrm{~g} / \mathrm{ml}\right)$, and the TBMA-MAA complex with $5-\mathrm{FU}\left(4 \cdot 10^{-7} \mathrm{~g} / \mathrm{ml}\right)$

The particle size was estimated at $13 \mathrm{~nm}$ for the complex with $5 \mathrm{~mol}$ $\% 5$-FU and $26.8 \mathrm{n}$ for the complex with 50 mol\% 5-FU.

The 5-FU release was estimated in two parallel experiments at $37^{\circ} \mathrm{C}$ One utilized a phosphate-citrate buffer (PCB) with $\mathrm{pH} 5.0$ to model the intracellular space and the other, a phosphate buffer (PB) with $\mathrm{pH} 7.4$ to model the intravascular space. Two systems, with 5 and 15 mol\% 5-FU, were chosen for testing (fig. 2, 3).
In both PB and PCB, 5-FU was released from the polymeric complex with 5 mol\% 5 -FU approximately 1.3 times faster than from the complex containing 5 mol\% 5-FU.

The kinetics of 5-FU release from the polymeric complex with TBMA-MAA (5 mol\% 5-FU) showed that the 5-FU release was $77.9 \%$ in PCB and $59.6 \%$ in PB over $52 \mathrm{~h}$ of dialysis (fig. 4).

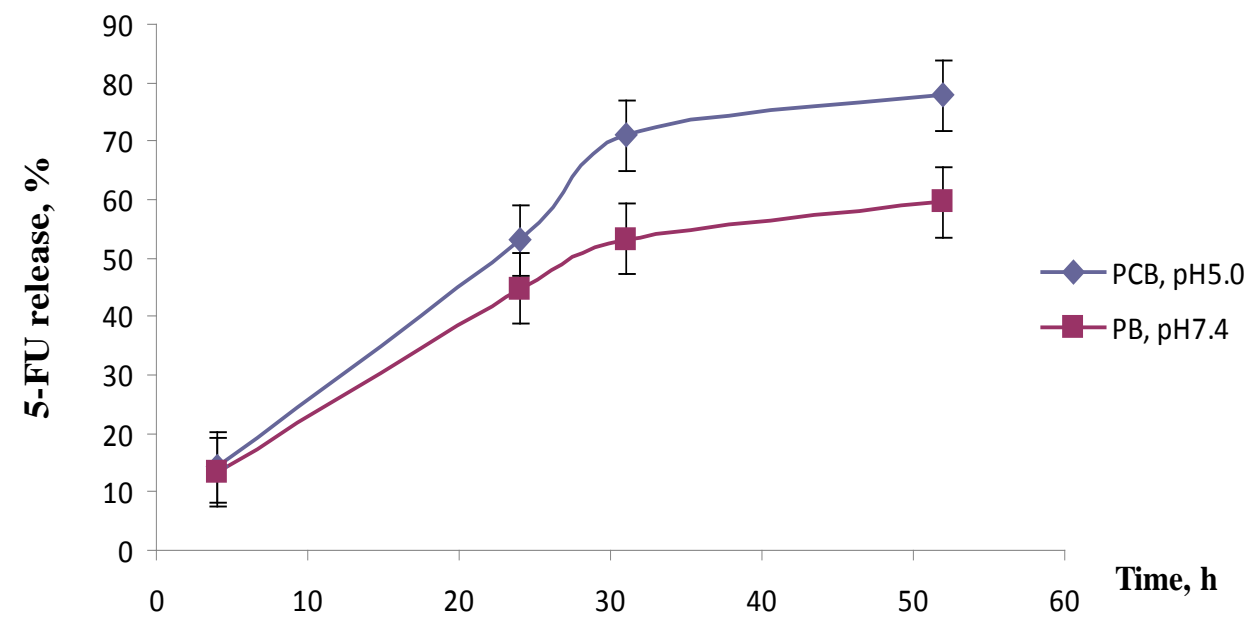

Fig. 4: Release of 5-FU from its polymeric complex with TBMA-MAA (5 mol\% 5-FU) 


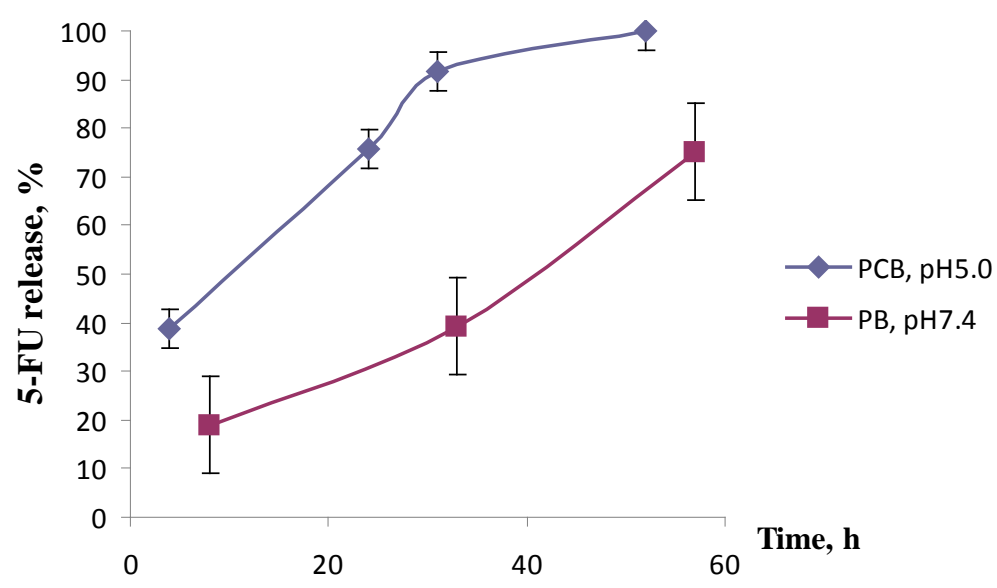

Fig. 5: Release of 5-FU from its polymeric complex with TBMA-MAA (15 mol\% 5-FU)

When the 5-FU release kinetics was studied with the TBMA-MAA polymeric complex containing $15 \mathrm{~mol} \% 5$-FU, the 5 -FU release was $100.0 \%$ in PCB and $75.1 \%$ in PB over 57 h of dialysis (fig. 5).

\section{CONCLUSION}

Water-soluble nanoscale complexes of 5-FU with TBMA-MAA copolymers extend application of 5-FU, while its general toxicity might be lower. The complexes are sufficiently stable at $\mathrm{pH} 7.4$ and readily release 5-FU at $\mathrm{pH} 5.0$. We have proposed the 5-FU polymer system as the basis for an injection pharmaceutical composition. The formation of the polymer complex in 5-fluorouracil. It is confirmed by IR spectroscopy and is consistent with the results of other researchers [21, 22]. A large amount of research directed to polymer systems 5-FU for oral administration. Currently, creation of polymeric derivatives of antitumor drugs is a promising direction of development of new pharmaceutical compositions [23-27]. These polymeric systems can alter the pharmacokinetics and increase the focus of the drug, while reducing the toxic effects on the body.

\section{AUTHORS CONTRIBUTIONS}

All the author have contributed equally.

\section{CONFLICT OF INTERESTS}

The authors have no conflict of interests to disclose.

Data used in the publication were obtained on the equipment of the center for collective use "Analytical Center of IMC RAS" (Nizhny Novgorod).

\section{REFERENCES}

1. Ofverholm A, Arkblad E, Skrtic S, Albertsson P, Shubbar E, Enerback C. Two cases of 5-fluorouracil toxicity linked with gene variants in the DPYD gene. Clin Biochem 2010;43:331-4.

2. Yoneda K, Yamamoto T, Ueta E, Osaki T. The inhibitory action of BOF-A2, a 5-fluorouracil derivative, on squamous cell carcinoma. Cancer Lett 1999;137:17-25.

3. Moehler M, Teufel A, Galle PR. New chemotherapeutic strategies in colorectal cancer. Recent Results Cancer Res 2005;165:250-9.

4. Goldberg RM, Sargent DJ, Morton RF, Fuchs CS, Ramanathan RK, Williamson SK, et al. Randomized controlled trial of reduced-dose bolus fluorouracil plus leucovorin and irinotecan or infused fluorouracil plus leucovorin and oxaliplatin in patients with previously untreated metastatic colorectal cancer: A North American Intergroup Trial. J Clin Oncol 2006; 24:3347-53.

5. Pohl A, Lurje G, Manegold PC, Lenz HJ. Pharmacogenomics andgenetics in colorectal cancer. Adv Drug Delivery Rev 2009;61:375-80.

6. Yarden Y, Baselga J, Miles D. Molecular approach to breast cancer treatment. Semin Oncol 2004;31:6-13.
7. Gunzburg WH, Lohr M, Salmons B. Novel treatments and therapies in development for pancreatic cancer. Expert Opin Investig Drugs 2002;11:769-86.

8. Nishiyama M, Eguchi H. Pharmacokinetics and pharmacogenomics in gastric cancer chemotherapy. Adv Drug Delivery Rev 2009;61:402-7.

9. Johnson KR, Young KK, Fan W. Antagonistic interplay between antimitotic and G1-S arresting agents observed in experimental combination therapy. Clin Cancer Res 1999;5:2559-65.

10. Fournier E, Passirani C, Colin N, Breton P, Sagodira S, Benoit JP. Development of novel 5-FU-loaded poly(methylidenemalonate 2.1.2)-based microspheres for the treatment of brain cancers. Eur J Pharm Biopharm 2004;57:189-97.

11. Saranya N, Moorthi A, Saravanan S, Devi MP, Selvamurugan N. Chitosan and its derivatives for gene delivery. Int J Biol Macromol 2011;48:234-8.

12. Mansouri S, Lavigne $\mathrm{P}$, Corsi $\mathrm{K}$, Benderdour M, Beaumont $\mathrm{E}$, Fernandes JC. Chitosan-DNA nanoparticles as non-viral vectors in gene therapy: strategies to improve transfection efficacy. Eur J Pharm Biopharm 2004;57:1-8.

13. Chung YC, Kuo CL, Chen CC. Preparation and important functional properties of water-soluble chitosan produced through maillard reaction. Bioresour Technol 2005;96:1473-82.

14. Yilmaz G, Demir B, Timur S, Becer CR. Poly (methacrylic acid)coated gold nanoparticles: functional platforms for theranostic applications. Biomacromolecules 2016;17:2901-11.

15. Tang H, Guo J, Sun Y, Chang B, Ren Q Yang W. Facile synthesis of pH sensitive polymer-coated mesoporous silica nanoparticles and their application in drug delivery. Int J Pharm 2011;421:388-96.

16. Fang W, Wang Z, Zong S, Chen H, Zhu D, Zhong Y, et al. pHcontrollable drug carrier with SERS activity for targeting cancer cells. Biosens Bioelectron 2014;57:10-5.

17. Hussain T, Ranjha NM, Shahzad Y. Swelling and controlledrelease of tramadol hydrochloride from a $\mathrm{pH}$ sensitive hydrogel. Des Monomers Polym 2011;14:233-49.

18. Weissberger A, Proskauer ES, Riddick JA, Toops EE. Organic solvents. Physical properties and methods of purification: INC., New York, LTD., London; 1955.

19. Bednarek E, Dobrowolski JCz, Dobrosz Teperek K, Sitkowski J, Kozerski L, Lewandowski W, et al. Theoretical and experimental 1H, 13C, 15N, and 170 NMR chemical shifts for 5halogenouracils. J Mol Struct 2000;554:233-43.

20. Graindourze M, Smets J, Zeegers Huyskens Th, Maes G. Fourier transform-infrared spectroscopic study of uracil derivatives and their hydrogen bonded complexes with proton donors: Part I. Monomer infrared absorptions of uracil and some methylated uracils in argon matrices. J Mol Struct 1990;222:345-64.

21. Vanarchi Rajini K, Praveen B Kajjari, Priya M Madalageri, Sakey Ravindra, Lata S Manjeshwar, Tejraj M Aminabhavi, et al. Blend hydrogel microspheres of carboxymethyl chitosan and gelatin for the controlled release of 5-fluorouracil. Pharmaceutics 2017;9:13. 
22. Kavitha K, Srinivasa Rao A, Nalini CN. An investigation on enhancement of solubility of 5-fluorouracil by applying complexation technique-characterization, dissolution and molecular-modeling studies. J Appl Pharm Sci 2013;3:162-6.

23. Hemant K, Raizaday A, Sivadasu P, Uniyal S, Kumar SH. Cancer nanotechnology: nanoparticulate drug delivery for the treatement of cancer. Int J Pharm Pharm Sci 2015;3:40-6.

24. Behera DK, Mishra K. Formulation and evaluation of chitosan-polypyrrole nanocomposites for controlled release of anticancer drug doxorubicin. Int J Appl Pharm 2019; 2:247-53.
25. Lee C, Saravanan M. Quantifying magnetite in chitosan microspheres loaded with 5-flurouracil using modified colorimetric method: a comparative study with thermogravimetric analysis. Int J Pharm Pharm Sci 2014;1:203-6.

26. Arias JL. Novel strategiesto improve theanticancer actionof 5fluorouracil byusing drugdelivery systems. Molecules 2008;13:2340-69.

27. Gu C, Le V, Lang M, Liu J. Preparation of polysaccharide derivates chitosan-graft-poly(e-caprolactone) amphiphilic copolymer micelles for 5-fluorouracil drug delivery. Colloids Surf B 2014;116:745-50. 